\title{
Once again about the basis of criminal liability in the aspect of modern criminal policy
}

\section{A. V. Ivanchin ${ }^{1}$}

${ }^{1}$ P. G. Demidov Yaroslavl State University, 14 Sovetskaya str., Yaroslavl 150003, Russian Federation

DOI: $10.18255 / 1996-5648-2021-3-370-377$

Research article Full text in Russian

The article shows the evolution of the normative model of the basis of criminal liability in soviet times and in recent history (during the period of the Criminal Code of the RSFSR in 1922, the Criminal Code of the RSFSR in 1926, the Criminal Code of the RSFSR in 1960 and the Criminal Code of the Russian Federation in 1996). The author substantiates the opinion that when determining the basis of criminal liability, the lawmaker should avoid extremes and strive to find the "golden mean". In this regard, the concept of a "dangerous state of personality", developed by representatives of the sociological school of law and introduced into the domestic criminal law almost a hundred years ago, is criticized. At the same time, the article proves the need to take into account, within reasonable limits and forms, in the process of criminal law-making, the dangerous properties of the criminal's personality. The author criticizes the criminal policy of recent years regarding the introduction of amendments to the Special Part of the Criminal Code of the Russian Federation, which are not consistent with art. 3, 8 of the Criminal Code of the Russian Federation (when the boundaries of the corpus delicti are vaguely formulated, not acts, but states are criminalized, etc.).

Keywords: Criminal Code of the Russian Federation; Criminal Code of the RSFSR; crime; basis; criminal responsibility; corpus delicti; theory of a dangerous state of personality; criminalization; special recidivism; differentiation of responsibility

INFORMATION ABOUT AUTHORS

Ivanchin, Artem V. $\mid$ E-mail: ivanchin@uniyar.ac.ru

Doc. Sc. (Jurisprudence), Associate Professor

Funding: Yaroslavl State University, Project VIP-015. 


\title{
Еще раз об основании уголовной ответственности в свете современной уголовной политики
}

\author{
А. В. Иванчин ${ }^{1}$
}

${ }_{1}^{1}$ Ярославский государственный университет им. П. Г. Демидова, ул. Советская, 14, Ярославль, 150003, Российская Федерация

DOI: 10.18255/1996-5648-2021-3-370-377

УДК 343.326

Научная статья

Полный текст на русском языке

В статье показана эволюция нормативной модели основания уголовной ответственности в советское время и в новейшей истории (в период действия УК РСФСР 1922 г., УК РСФСР 1926 г., УК РСФСР 1960 г. и УК РФ 1996 г.). Автор обосновывает мнение о том, что при определении основания уголовной ответственности правотворцу следует избегать крайностей и стремиться к поиску «золотой середины». В этой связи критикуется концепция «опасного состояния личности», разработанная представителями социологической школы права и внедренная в отечественный уголовный закон без малого сто лет назад. При этом в статье доказывается необходимость учета в разумных пределах и формах в процессе уголовного правотворчества опасных свойств личности преступника. Автором критикуется уголовная политика последних лет в части внесения в Особенную часть УК РФ поправок, которые не согласуются со ст. 3, 8 УК РФ (когда размыто формулируются границы состава преступления, криминализируются не деяния, а состояния, и т. д.).

Ключевые слова: УК РФ; УК РСФСР; преступление; основание; уголовная ответственность; состав преступления; теория опасного состояния личности; криминализация; специальный рецидив; дифференциация ответственности

ИНФОРМАЦИЯ ОБ АВТОРАХ

Иванчин, Артем Владимирович $\mid$ E-mail: ivanchin@uniyar.ac.ru

Доктор юридических наук, доцент

Финансирование: ЯрГУ, проект VIP-015.

В 2022 г. исполнится ровно сто лет с момента принятия постановления Всероссийского Центрального Исполнительного Комитета, подписанного «всесоюзным старостой» М. И. Калининым, согласно которому с 1 июня 1922 г. в нашей стране был введен в действие Уголовный Кодекс РСФСР 1922 г. Нормативная модель основания уголовной ответственности по УК 1922 г. была выражена в ряде его статей и выглядела следующим образом (курсив наш. - А. И.): 
1) «УК РСФСР имеет своей задачей правовую защиту государства трудящихся от преступлений $u$ от общественно опасных элементов и осуществляет эту защиту путем применения к нарушителям революционного правопорядка наказания или других мер социальный защиты» (ст. 5);

2) «Преступлением признается всякое общественно опасное действие или бездействие, угрожающее основам советского строя и правопорядку, установленному рабоче-крестьянской властью на переходный к коммунистическому строю период времени» (ст. 6);

3) «Опасность лица обнаруживается совершением действий, вредных для общества, или деятельностью, свидетельствующей о серъезной угрозе общественному правопорядку» (ст. 7);

4) «В случае отсутствия в Уголовном кодексе прямых указаний на отдельные виды преступлений, наказания или меры сочиальной защиты применяются согласно статьям Уголовного Кодекса, предусматривающих наиболее сходные по важности и роду преступления, с соблюдением правил общей части сего Кодекса» (ст. 10);

5) «Лица, признанные судом по своей преступной деятельности или по свлзи с преступной средой данной местности социальноопасными, могут быть лишены по приговору суда права пребывания в определенных местностях на срок не свыше трех лет» (ст. 49) [1].

В 1926 г. был принят новый УК РСФСР (точнее говорить, «новая редакция УК 1922 г.»). Нормативная модель основания уголовной ответственности по УК 1926 г. была во многом сходной с закрепленной в УК 1922 г. (сохранены определение преступления и аналогия закона и т. д.). Правда, появилась норма о малозначительности: «Не является преступлением действие, которое хотя формально и подпадает под признаки какой-либо статьи Особенной части настоящего Кодекса, но в силу явной малозначительности и отсутствия вредных последствий лишено характера общественно-опасного» (примечание к ст. 6).

Вместе с тем в УК 1926 г. еще более рельефно были выражены классовые начала предыдущего Кодекса: «В отношении лиц, совершивших общественно-опасные действия или представляющих опасность по своей связи с преступной средой или по своей прошлой деятельности применяются мерь соииалъной защиты судебно-исправительного, медицинского, либо медико-педагогического характера» (ст. 7) [2]).

Квинтэссенцией классовой направленности УК 1922 г. и УК 1926 г. явилась возможность применения мер уголовной ответственности не только за конкретно совершенное преступление, но и в отношении лиц, опасных в силу своей связи с преступной средой или прошлой деятельности. Тем самым на законодательном уровне была воспринята теория «опасного состояния личности», разработанная представителями социологической школы уголовного права. Идейные вдохновители социологической школы (Ф. Лист, А. Принс и др.) исходили из того, что человек может представлять для общества опасность по своим индивидуальным особенностям независимо от совершения этим лицом преступления, и считали необходимым 
Еще раз об основании уголовной ответственности...

применять самые кардинальные меры репрессии к таким «опасным» лицам. Добавим также, что меры уголовной ответственности, поименованные в УК 1922 г. как наказания и меры социальной защиты, в УК 1926 г. в целом стали обозначаться последним термином, т. е. мерами социальной защиты. Но в целом можно сказать, что УК 1922 г. и УК 1926 г. явили собой торжество идей социологической школы уголовного права.

Не удивительно, что данная законодательная модель основания уголовной ответственности послужила хорошим инструментом для чудовищных репрессий сталинского времени. УК 1926 г. действовал до вступления в силу УК 1960 г., т. е. до 1961 г., и именно на основании УК 1926 г. были произведены самые масштабные классовые «чистки» нашего народа, хорошо проиллюстрировавшие, что такое теория «опасного состояния личности» в своем реальном действии. Данная концепция впоследствии была по достоинству оценена в доктрине. «Идея “опасного состояния", - пишет профессор А. В. Наумов, - одно из самых реакционных изобретений уголовно-правовой теории. Замена наказания мерами безопасности на деле означает отрицание основных институтов уголовного права, игнорирование принципа ответственности за вину в совершении предусмотренного уголовным законом общественно опасного деяния. Идеи социологической школы позже нашли свое отражение, например, в итальянском Уголовном кодексе 1931 г., принятом во времена господства в стране фашистского режима» [3, с. 531-532]. Действительно, наш народ заплатил слишком большую цену за внедрение указанной теории в уголовный закон.

В УК РСФСР 1960 г. наиболее одиозные и отмеченные выше положения социологической школы, нашедшие отражение в фрормуле основания уголовной ответственности, были заменены на разработанные классической школой уголовного права. Основанием ответственности было признано преступление (определенное формально-материально), аналогия запрещена, место мер социальной защиты заняли наказания и т. д. Но тем не менее личность преступника продолжала играть немалую роль в криминализации и диффреренциации ответственности, например, опасные свойства личности преступника выступали криминообразующим признаком, когда в основной состав вводилось условие об административной преюдиции, и часто использовались как квалифицирующее обстоятельство, в частности, путем указания на совершение преступления рецидивистом.

Что происходило далее при разработке и принятии УК 1996 г., хорошо известно специалистам и не нуждается в подробном пересказе. Возобладала идея максимального ухода от личности в обосновании уголовной ответственности. Акцент был перенесен с преступника на преступление. Фактор личности в процессе криминализации был практически полностью нивелирован (исключена административная преюдиция в «чистом виде» и т. д.). И даже в, казалось бы, очевидных феноменах, связанных с личностью, была предпринята попытка перенести фрокус внимания на объективные свойства деяния. Например, понятие рецидивиста была заменено понятием рецидива преступлений. 
В нормативной модели основания уголовной ответственности в УК РФ 1996 г. обрели завершенный вид идеи классической школы уголовного права: 1) принцип законности предписывает определять преступность деяния исключительно на основании норм УК РФ и запрещает аналогию уголовного закона (ст. 3); в ст. 8 основанием уголовной ответственности, которое фактически возведено в ранг самостоятельного принципа уголовного права, признается деяние, содержащее состав преступления (по сути дела преступление; состав обозначен здесь как эталон квалификации); преступление определяется по формально-материальной формуле и лишено классового характера (ч. 1 ст. 14); а ч. 2 ст. 14 позволяет преодолеть излишний формализм уголовного права, позволяя признать непреступным (малозначительным) любое деяние, предусмотренное УК, если оно не опасно. Вот эти положения и образуют каркас современной модели основания уголовной ответственности, причем они прошли солидную проверку временем (в этом году, как известно, отмечается юбилей УК РФ, который был принят 25 лет назад).

Правда, с течением времени (в период действия УК 1996 г.) уголовная политика государства неоднократно менялась. Можно говорить, в частности, о проникновении (пусть и фрагментарном) идей социологической школы уголовного права в современное российское уголовное законотворчество, но не прямым путем - через изменение перечисленных норм Общей части УК, а посредством корректировки Особенной части. Так, все мы знаем историю возвращения в прямом виде административной преюдиции в УК РФ. Более того, число составов преступлений с указанным признаком постепенно растет. Например, Федеральным законом от 30.12.2020 № 525-ФЗ условие о предшествующем привлечении к административной ответственности было введено в составы преступлений, предусмотренные ч. 2 и ч. 3 ст. 330.1 УК (злостное уклонение от исполнения обязанностей, предусмотренных законодательством РФ, в связи с признанием лица выполняющим функции иностранного агента).

Кроме того, несмотря на сохранение в Общей части УК РФ вполне сбалансированных положений об основании уголовной ответственности (ст. 3, 8, 14 и др.), в Особенной части начинают появляться нормы, в которых ответственность «привязана» к опасному «состоянию» личности. Так, Федеральным законом от 01.04.2019 № 46-ФЗ была введена ст. 210.1 УК «Занятие высшего положения в преступной иерархии». Своеобразие данной новеллы заключается в том, что основанием уголовной ответственности она признает не конкретное деяние, которое, в силу ст. 8 и 14 УК РФ, должно им выступать, а статус (положение) лица в криминальном мире. Это, конечно, не уголовное преследование представителей «класса эксплуататоров» (помещиков, дворян и др.), а позже «кулаков» и политически неблагонадежных элементов, как это было в ходе репрессий советского времени, но в некотором смысле реанимация теории «опасного состояния личности». Понятно, что сделано это из самых лучших побуждений (усиление борьбы с организованной и профессиональной преступностью), но, как известно, «благими намерениями вымощена дорога в ад». Тем более что к таким средствам ради 
Еще раз об основании уголовной ответственности...

достижения желаемой цели прибегать нет смысла, если учесть современные возможности по доказыванию конкретной криминальной активности лидеров и членов организованных групп и преступных сообществ (красноречивой иллюстрацией чего является дело Захария Калашова («Шакро Молодого»), отправленного «за решетку» на длительный срок).

Оценивая колебания современной уголовной политики в вопросах основания уголовной ответственности, позволим себе высказать собственные соображения на этот счет, являющиеся плодом достаточно длительного осмысления указанных вопросов.

Первый тезис. С ним, пожалуй, никто не будет спорить. С учетом нашего исторического прошлого (в частности, норм УК 1922 г. и УК 1926 г., написанных под диктовку сторонников социологической школы права, и опыта его применения, особенно в годы сталинских репрессий) мы должны свято хранить и оберегать от "посягательств» нынешнюю модель основания уголовной ответственности, закрепленную в Общей части УК РФ (ст. 3, 8, 14). Двойственность в регулировании основания уголовной ответственности, когда ей подвергаются не только лица, совершившие преступление, но и лица, опасные для общества на взгляд власти, - основа беззакония и произвола. Об этом следует помнить столь же хорошо, сколь отчетливо мы помним о страшных по своему масштабу последствиях внедрения этой модели в уголовный закон. В связи с этим критической оценке следует подвергать, по нашему мнению, и любые попытки отступить от положений Общей части УК при внесении изменений в его Особенную часть (имеются в виду и случаи криминализации некоего опасного состояния лица, как в ст. 210.1, и конструирование составов преступлений с аморфными границами, как, например, в ст. 238 УК).

Второй тезис. В вопросах учета опасных свойств личности преступника в процессе криминализации, дифференциации и индивидуализации уголовной ответственности необходимо придерживаться, по нашему глубокому убеждению, «золотой середины» (aurea mediocritas). Это понятие со времен древнегреческой фрилософрии (в трудах Аристотеля и др.) означает желанную середину между двумя нежеланными крайностями (добродетель храбрости лежит посередине между пороками безрассудства и трусости и т. д.). Конечно, и это абсолютно закономерно и логически выверено, центр тяжести при определении реакции государства (и ее объема) на противоправное поведение должен приходиться на объективные свойства деяния: его объект, размах, способ, вредные последствия и т. д. Затем учету подлежат субъективные признаки: сначала фрорма и вид вины, потом цели и мотивы. И, наконец, принимаются во внимание признаки субъекта преступления: сначала общие (в частности, возраст), а затем и специальные, в том числе характеризующие опасность личности (прежде всего предшествующее противоправное поведение).

С этих позиций модель основания уголовной ответственности, закрепленная в УК РСФСР 1922 г. и УК РСФСР 1926 г., не просто крайность, а запредельная степень ее проявления. Разрешение аналогии и возможность 
Иванчин А. В.

применения мер репрессии к лицу, не совершившему противоправного деяния, конечно, страшная страница в истории отечественного уголовного права. И наша задача - сделать все, чтобы никогда не повторить этот урок. Но при этом не следует ударяться и в другую крайность, когда опасность личности вообще исключается из детерминант криминализации или дифференциации ответственности. Причем учет опасных свойств личности преступника должен возрастать, по нашему мнению, при переходе от процесса криминализации к дифференциации уголовной ответственности, а затем к ее индивидуализации. То есть при установлении уголовно-правового запрета опасность личности должна учитываться самъм минимальным образом (в строго ограниченных бормах и пределах), в прочессе ди бббереничации - в большей степени и, наконец, максилально полно - при индивидуализации ответственности. Так, если говорить о признаке административной преюдиции как средстве криминализации, то его оптимальное использование нам видится следующим. Основание криминализации - общественная опасность поведения. Очевидно, что в абсолютном большинстве случаев она определяется исключительно объективными свойствами акта человеческого поведения: его объектом, свойствами самого деяния или его последствий и т. д. Поэтому, например, при криминализации убийства и причинения смерти по неосторожности, похищения человека или изнасилования и т. д., и т. п. ни о какой преюдиции и речи идти не может. В этих случаях, коих львиная доля, общественная опасность содеянного налицо и без предшествующего привлечения субъекта к административной ответственности.

В равной мере абсолютное большинство административных правонарушений, даже будучи многократно повторенными, не достигает того уровня опасности, который характерен для преступлений. Ясно, например, что даже десятки случаев перехода одним и тем же человеком дороги на запрещающий сигнал светофрора или превышение скорости сами по себе (без соответствующей тяжести последствий) будут недостаточны для криминализации (но опять-таки все относительно, и даже по таким нарушениям нужно внимательно отслеживать их структуру и динамику).

Получается, что лишь в единичных случаях совершения административных нарушений, степень вредоносности которых достаточно высока (хотя однократно и не достигает границы общественной опасности), когда меры предшествующего административного реагирования не дают результата, ибо субъект упорно их игнорирует, государство вправе ставить вопрос о криминализации такого поведения. С этих позиций широкое использование инструмента административной преюдиции - такая же крайность, как и его полное забвение. Вот почему мы в целом приветствуем существующий курс законодателя на дозированное использование данного признака при конструировании основных составов преступлений (причем и на его сочетание с признаком предшествующей судимости, как это, например, логично сделано в ст. 264.1 УК РФ).

При диффреренциации же ответственности возможно более широко (в сравнении с процессом криминализации) использовать квалифици- 
рующие признаки, указывающие на опасные свойства личности (прежде всего специальный рецидив). И здесь в УК РФ имеется огромный резерв для углубления и упорядочения дифференциации ответственности. Примечательно, что за четверть века действия УК РФ позиция законодателя в этом вопросе последовательностью не отличалась. В момент принятия УК 1996 г. признак специального рецидива (тождественных или однородных преступлений) достаточно часто встречался в его нормах. Например, в статьях о хищениях ответственность за их совершение усиливал признак совершения преступления «лицом, ранее два или более раза судимым за хищение либо вымогательство». Но уже в 2003 г. этот и ему подобные квалифицирующие признаки были исключены из УК, равно как и ликвидировано понятие неоднократности. Затем в отдельных статьях Особенной части признак специального рецидива стал вновь появляться. Так, все мы помним, когда в 2012 г. в ст. 131, 132, 134 и 135 УК РФ появились части с наиболее строгой санкцией за совершение преступления «лицом, имеющим судимость за ранее совершенное преступление против половой неприкосновенности несовершеннолетнего».

Очередной раз об этом приеме законодатель вспомнил в 2016 г., когда вводил в УК нормы о мелком взяточничестве и мелком коммерческом подкупе (ст. 291.2, 204.2 УК РФ), ответственность за которые была усилена посредством указания на лицо, имеющее судимость за совершение соответствующих коррупционных преступлений. В итоге никакой системности в вопросе учета данного квалифицирующего признака в УК РФ не наблюдается. Абсолютно непонятно, почему за указанные выше преступления (половые и коррупционные) ответственность градирована с помощью специального рецидива, а за большинство иных преступлений - нет. Причем есть немало преступлений, которые, согласно многочисленным официальным данным, становятся профессиональной специализацией криминалитета (хищения, наркопреступления, фральшивомонетничество и т. д.). Совершенно очевидно, что в вопросах учета (а по фракту - неучета) криминального прошлого субъекта в процессе дифференциации ответственности действующая редакция УК РФ 1996 г. в определенном смысле являет собой такую же крайность, каким являлись УК 1922 г. и УК 1926 г. с его теорией «опасного состояния личности». Еще раз призовем отечественного законодателя к поиску «золотой середины» в этом вопросе. Если мы хотим серьезно заниматься профрилактикой профессиональной и организованной преступности, необходимо самым тщательным образом относиться к обеспечению полноты и системности регламентации рецидива преступлений в Общей и Особенной частях УК (кстати, давно пора начать называть вещи своими именами, вернувшись к старому, но более точному названию «рецидивист»).

\section{Ссылки}

1. Уголовный Кодекс Р.С.Ф.С.Р. 1922 года // СПС «КонсультантПлюс».

2. Уголовный Кодекс Р.С.Ф.С.Р. 1926 года // СПС «КонсультантПлюс».

3. Наумов А. В. Преступление и наказание в истории России: в 2 ч. М., 2014. Ч. І. 752 c. 